\title{
A review of educational and legislative strategies to promote bicycle helmets
}

\author{
Philip L Graitcer, Arthur L Kellermann, Tom Christoffel
}

Bicycling is a universal and popular means of transportation. Worldwide, there are three times as many bicycles produced each year as automobiles. ${ }^{1}$ In the US, an estimated 67 million bicyclists ride a total of 15 billion hours annually. ${ }^{2}$ About 27.5 million of these bicyclists ride bicycles at least once a week. About $46 \%$ of the bicyclists are under 16 years old. ${ }^{3}$

Besides being extremely popular, bicycles are also a substantial source of mortality, morbidity, and disability. In the US, each year, there are more than 580000 hospital emergency room visits associated with bicycles. When other medically treated injuries are counted, such as injuries treated in physicians' offices, there may be a total of more than one million medically attended injuries involving bicycles each year. ${ }^{4}$ There are about 1000 deaths and about 20000 persons with bicycle injuries admitted to hospitals. ${ }^{5}$ The annual estimated economic costs in the US is about $\$ 8$ billion, representing an average expected injury cost of about $\$ 120 /$ rider/year. ${ }^{2}$ Bicyclists' risk of death, based on distance travelled, is three times that of motorists, and their risk of serious non-fatal injury is nine times that of motorists (JG Mathieson, seminar on cyclists and law compliance, Geelong, Australia, 29-30 April 1991; unpublished).

The most serious bicycle injuries are head injuries. ${ }^{6}$ About 65 000-100 000 emergency room visits, $40 \%$ of all hospital admissions, and $62-90 \%$ of all bicycle crash fatalities involve head injuries. ${ }^{78}$

Two case-control studies have demonstrated that bicycle helmets are effective in preventing mortality and morbidity from bicycle crash related head injuries. Thompson and his colleagues estimated that bicyclists not wearing helmets had a 6.67 increased relative risk of head injury compared with bicyclists wearing helmets. ${ }^{9}$ In Brisbane, Australia, Thomas showed that the risk of injuries to the upper head was 2.7 times higher among non-helmet wearers compared with helmet wearers. ${ }^{10}$

In spite of this documented effectiveness, overall helmet use among bicyclists in the US was estimated in 1992 to be less than $18 \%{ }^{2}$ Helmet use varies among age groups; it is highest in the $41-50$ age group (about 25\% reported rate), and lowest in the 11-14 age group (about $11 \%$ reported rate). ${ }^{2}$ According to a survey recently conducted by the US Consumer Product Safety Commission, over half of the bicyclists who do not wear helmets stated that they never thought about it; almost
$16 \%$ had not got around to wearing one; $21 \%$ felt that helmets were unnecessary; and nearly $19 \%$ did not wear helmets because they did not ride in traffic. ${ }^{2}$

In the past decade there have been a variety of educational approaches used to promote the use of bicycle helmets. These programs have included classroom curricula, programs that subsidize the purchase of helmets, and programs that provide helmets in a health care setting. None of these individual educational strategies has been shown to have any significant impact in increasing helmet use. Only helmet promotion programs that are organized by community wide coalitions and use a variety of educational and publicity strategies have been shown to be effective. The most successful of these programs - the Seattle Children's Bicycle Helmet Campaign organized by Harborview Injury Prevention and Research Center - used multiple strategies. These included classroom education, discount purchase programs, bike rodeos, distribution of printed material through a variety of venues, and intensive promotional efforts by sports leaders, bicycle clubs, and the media to increase children's helmet use. ${ }^{11}$ Using this broad based approach, the Harborview program has been able to increase helmet wearing rates among children to more than $40 \% \cdot{ }^{12}$ No information is available on the direct and indirect costs of these promotional efforts.

The relative difficulty in implementing educational programs to promote helmet use, their potentially great cost, and their limited success in greatly increasing helmet use, have led to the introduction of mandatory helmet wearing laws as a principle strategy of many governmental jurisdictions. In this paper, we will examine the impact of several educational campaigns on helmet use, review the early experience two programs have had with the introduction of helmet laws, and place their experiences in the context of the overall reduction of bicycle related injuries. We will also examine what behavioural, biomechanical, and operational research is needed to support further efforts to reduce bicycle caused head injuries.

\section{Educational strategies}

Education is usually the first and most commonly used strategy to implement an active intervention. The basic concept is that education can provide the information and training 
that will bring about a fundamental change in an individual's behavior. Although health education strategies have been successfully and rigorously applied to the prevention and control of chronic disease problems such as hypertension, coronary heart disease, and diabetes, health education has been directed to the prevention of injuries to a much lesser degree. Environmental design, regulations, and legislation have been used more frequently to reduce the incidence of injury morbidity and mortality. ${ }^{13}$ The effectiveness of educational strategies depend on the degree to which factors associated with helmet use and non-use are applied, and to the adherence of these strategies to health education principles involving program design, implementation, and evaluation. For bicycle helmets, education usually focuses on informing the user about helmet protection and encouraging him/her to use it whenever riding a bicycle. Anecdotally, there have been many attempts by public health, traffic safety, and community groups to increase the use of bicycle helmets. Unfortunately, reports of these programs and their successes and failures are found infrequently in the literature. Those reports that are published often have inherent design deficiencies such as inadequate sample size, inappropriate use of, or failure to select, comparison groups, and they use indirect measures for head injury reduction (self reports) or helmet use (self reporting or parental reporting) that make comparison with other studies difficult. We will report on those educational campaigns that have minimized these deficiencies.

\section{School programs}

School based educational programs provide ready access to likely bicyclists-childrenand also offer additional advantages over other strategies because they allow educational messages to be targeted to different age groups, have a captive audience ready to learn, and provide professional educators to convey the injury prevention message.

In Augusta, Georgia, two schools were selected for a comparison of the effectiveness of education to promote helmets. In one school, intensive educational activities were carried out with children and their parents including organizing a bicycle safety club, establishing special bicycle safety programs, and the distribution of a literature packet on bicycle safety that also included a coupon valid for a $\$ 10$ discount on the purchase of a helmet. At a similar school that did not receive these interventions, only the literature packet and the discount coupon were distributed. Questionnaires were completed before and after intervention by parents and children at both schools. Between the two schools there were no significant differences in parents' reporting of helmet use, their children's use or ownership, or on the children's own reports of helmet use or ownership. Despite the absence of statistically demonstrable effects of the intervention, there was an increase in both schools in positive helmet behavior, such as wearing or owning helmets. ${ }^{14}$ Because there was no community control group, it is not possible to determine if this observed increase in helmet wearing was related to either school's education programs. In a Canadian study, a comprehensive bicycle helmet awareness program that included classroom teaching, poster design contests, and schoolwide activities focusing on helmet wearing, showed no impact on the observed rate of helmet wearing among the children riding their bicycles to school. ${ }^{15} \mathrm{~A}$ subsidy offered to reduce the purchase price of helmets for children at a third school did increase the number of helmets owned and somewhat increased their use, leading the authors to suggest that an educational program and a subsidy program can increase helmet use.

\section{Physician's offices}

Physician's offices - especially pediatric practices - are often chosen as a locus for educational strategies. Physicians and their staff have frequent access to their patients, and because they are viewed by their patients as authority figures, their recommendations are often given priority.

Parents of children receiving routine ambulatory treatment in a pediatrician's or family practitioner's office were randomly selected and given counselling by the physician on the need for their children to wear bicycle helmets. Follow up surveys of subsequent helmet purchases indicated that there was little difference in purchase rate between those parents who did and did not receive counselling. ${ }^{16}$ In a similar study, parents of children presenting to an emergency room with a bicycle injury were randomly selected and given physician counselling and printed information on the need to purchase and wear a bicycle helmet; as before there was little difference between those parents who received counselling and those who did not. ${ }^{17}$ The authors stated that they were surprised that physician counselling made no additional impact on the purchase of helmets. Similar findings were seen in a study to promote child car seats through physician counselling with parents. ${ }^{18}$ The American Academy of Pediatrics (AAP) supported a bicycle helmet promotion program through 25 local AAP chapters. Pediatricians were provided with informational material for children and their parents. In addition, parents were given the opportunity to purchase helmets at a discounted price through the mail. Over 100000 helmets were sold, though no measure of this program's long term impact on increasing helmet wearing or reducing injuries has been made. ${ }^{19}$

\section{Subsidy programs}

Some helmet advocates have suggested that parents are sometimes unable to afford to purchase helmets for their children. To overcome these financial barriers, governments have participated in programs to provide dis- 
counted helmets or to puchase helmets at below retail cost. In one study in Toronto, children in three schools in low income neighborhoods were offered helmets for $\$ 10$. Observations of helmet use were made in neighborhoods where these schools were located and in three other schools in similar neighborhoods in which children did not receive discounted helmets; no difference in helmet use was observed in either neighborhood. The authors conclude that the observational data do not support the theory that helmet subsidies would increase helmet use. ${ }^{20}$ In contrast, Rivara and his colleagues observed that in the Seattle helmet campaign discount coupons may have been the most effective among the many strategies used for helmet promotion. ${ }^{12}$

\section{Community programs}

The most common - and most successful campaigns to promote helmet use incorporate a combination of publicity, educational, and helmet distribution strategies. In the US, many community programs have been modelled after campaigns developed by the National SAFE KIDS Campaign or the Harborview Injury Prevention and Research Center in Seattle, Washington. Beginning in 1986, a multifaceted campaign was developed involving a coalition of health, bicycle, and helmet industry organizations in Seattle. The major goals of this campaign were to convince parents about the hazards of riding bicycles without helmets, to lower the price of helmets, and to overcome children's reluctance to wear helmets. ${ }^{11}$ After six years of intensive community activities focused on children and their parents, the observed helmet use among children in Seattle increased from $1 \%$ to $40 \%$ in $1992 .{ }^{12}$ These results were achieved through comprehensive and intensive community wide efforts that included stories in print and electronic media, public service announcements, press conferences, posters, brochures, stickers, health fairs, bike rodeos, school and youth programs, and distribution of discount coupons. During 1987 and 1988, the impact of the Seattle program on observed children's helmet use was compared with Portland, Oregon, where there was no community promotion program. Observed helmet use increased from $4.6 \%$ to $14.0 \%$ in Seattle and from $1.0 \%$ to $3.6 \%$ in Portland. ${ }^{21}$ Children were more likely to be wearing helmets when their adult or child companions were also wearing helmets. The impact of companionship in promoting helmet use has also been documented in another study. ${ }^{22}$

\section{Enforcement strategies}

In light of the limited success of single educational strategies, and the documented effectiveness of bicycle helmets, mandatory helmet laws are being enacted to promote bicycle helmet use. Since 1990, when Victoria, Australia introduced what is believed to be the first law requiring wearing of helmets for all bicyclists, enforcement has become increasingly popular as a strategy to increase use. Compared with educational strategies, mandatory laws for bicycle helmet use are relatively easy to implement and helmet wearing is not an unusual hardship on individuals. To date, evaluation of the effectiveness of enforcement has been reported for only two jurisdictions - Victoria, Australia, and Howard County, Maryland however, Australia, New Zealand, Ontario, Canada, and American states containing 45\% of the American population have already passed, or are considering, passage of laws that require the wearing of helmets. In this section, we will review the experience of Australia and Maryland and discuss their implications for the future of helmet laws.

\section{VICTORIA, AUSTRALIA}

A comparison study of injury patterns among bicyclists and motorcyclists during the period 1975 to 1980 was conducted, when less than $5 \%$ of all Victorian bicyclists wore helmets, but all motorcyclists had been required to wear helmets since 1961. Although there were 2-3 times more motorcyclist injuries than bicyclist injuries overall, twice as many bicyclists as motorcycle riders sustained head injuries. ${ }^{23}$ These results stimulated the Victorian Road Traffic Authority, along with a number of community voluntary and commercial groups, to organize promotional campaigns to increase bicycle helmet use in the state.

\section{Pre-law helmet promotion}

Beginning in 1980, a bicycle education curriculum was taught in the schools. In 1982, a trial bulk purchase program in the schools permitted parents to purchase helmets at approximately two thirds of retail cost. In 1983, the Education Department instituted a policy that required helmet wearing at all school cycling activities. In 1984, a major helmet promotion campaign was focused on young boys and girls and on their parents. Al activities took place in the elementary school setting. Market research had shown that boys over 12 years had strong negative reactions against helmets and were extremely sensitive to peer pressure, while younger boys and girls (5-11 years) were less likely to resist helmet campaigns and their mothers were more likely to recognize the seriousness of head injuries. This market research also identified financial barriers to the purchase of helmets. The 1984 campaign included a number of new activities including point of sale materials and posters promoting helmets, involvement of bicycling clubs, dissemination of information to school principals and school councils, articles on bicycle helmet safety in local newspapers, posters and information to physicians, radio and television commercials, bulk purchase programs, and a rebate program in which the Victorian Government offered $\$ 10$ for all purchases of Australian made, approved helmets during a certain time period. ${ }^{24}$

Helmet use steadily increased during these promotion campaigns as seen in figure 1 . In 


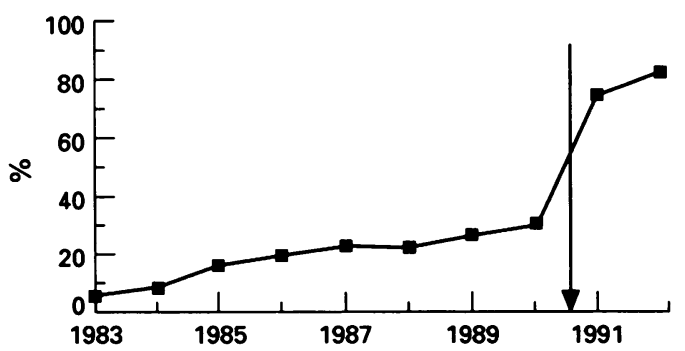

Figure 1 Estimated helmet wearing rates in Victoria, 1983-92 (arrow indicates introduction of law to enforce helmet wearing on 1 fuly 1990).

1985 , as helmet use rates rose, the Minister for Transport felt because there was an established base of helmet wearing in Victoria, the political climate was such that it would soon be possible to make bicycle helmets compulsory. After 10 years of promotion activities, a state wide law requiring the wearing of bicycle helmets for all bicyclists became effective on 1 July 1990.

\section{Post-law usage rates}

In March 1991, approximately nine months after implementation of the law, the average use rate for Victoria bicyclists was $75 \cdot 2 \%$. A special survey, conducted in May 1992, indicated that this rate increased further to $83 \% .^{25}$

\section{Injuries}

The number of bicyclists killed or admitted to hospital with head injuries in Victoria fell during the period of the bicycle helmet education campaign held between July 1981 and June 1990. In the year after the passage of the mandatory helmet law, the number of head injuries decreased by $48 \%(1990 / 1)$. An additional decline to $70 \%$ of the pre-law levels was noted in 1991/2. Bicyclist head injuries based on pre-law data indicate that in 1992 the proportion of cases with head injury was significantly less than projected, based on trends derived from events that occurred before 1990 (figure 2). ${ }^{25}$

\section{Bicycle use}

Critics of mandatory helmet legislation expressed concern that laws could negatively affect bicycle use for a variety of reasons: cost of helmets, inconvenience, or social unacceptability among certain peer groups. After passage of the Victoria law, there was a reduction in bicycle usage in 12-17 year old children of $42 \%$ in 1991 and $45 \%$ in 1992 , relative to data collected in 1990. Among children 5-11 years, bicycle use decreased: $3 \%$ in 1991, and $11 \%$ in 1992, compared with 1990 . Adult bicycle use was not surveyed in 1990, but comparable data from a survey conducted during November 1987 to January 1988 , indicated an increase in adult bicycling activity of $86 \%$ in 1991 , and an increase of $100 \%$ in $1992 .{ }^{25}$ This decline in bicycle usage in children and adolescents may be due to their resistance of wearing helmets, although a state wide economic recession and a

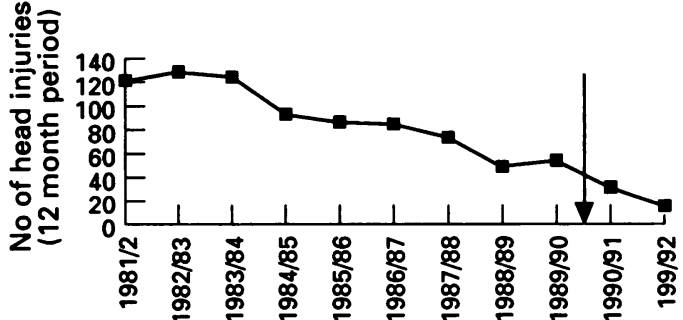

Figure 2 Head injuries in bicyclists in metropolitan Melbourne, 1981-92.

recent law reducing the age at which motor vehicle operators' permits are issued are also plausible explanations for this decrease.

\section{HOWARD COUNTY, MARYLAND}

On 1 October 1990, the first US law mandating the wearing of helmets for all children younger than the age of 16 was passed in Howard County, Maryland. Although the law was preceded by the organization of school and community bicycle safety programs that recommended the use of helmets, actual passage of the law was precipitated by the deaths of two children within a nine month period as a result of bicycle related injuries. ${ }^{26}$

Based on observation, the helmet use among children in Howard County increased from $4 \%$ to $47 \%$ after the implementation of the law. Compared with two nearby counties where there were no helmet laws in place, helmet use increased from $8 \%$ to $19 \%$ in one and decreased from $19 \%$ to $4 \%$ in the other over the same time period. ${ }^{26}$

The impact of education and the Howard County law was evaluated in comparison with two nearby counties, one of which had a bicycle education program that included helmet promotion activities (Montgomery County), the other (Baltimore County) did not have any substantial legislative or promotional activities. Three months before the implementation of the helmet law, children in Howard County reported in a postcard survey that they wore helmets 'always' or 'usually' nearly $11 \cdot 4 \%$ of the time they rode bicycles. Eight months after passage of the helmet law, $37.5 \%$ of them reported they wore helmets. ${ }^{27}$ In Baltimore County, self reported usage increased from $6.7 \%$ to $11 \cdot 1 \%$. In Montgomery County, helmet usage rose from $8.4 \%$ to $12.6 \%$ during the same period. In spite of the bicycle educational program in Montgomery County, helmet use was significantly less than it was in Howard County, and was not significantly different than that of Baltimore County, where no educational activities took place. In comparison, education activities combined with the helmet law substantially increased the rate of helmet wearing. ${ }^{28}$

\section{Extent of legislation}

As of May 1994, bicycle helmet wearing has been made mandatory in all states and territories in Australia, in New Zealand, in nine 
states in the US, and in at least 17 local US communities. In October 1995, helmet use will become mandatory in Ontario, Canada. In the US, helmet legislation has been proposed but not yet implemented in another 12 states (table).

The success of mandatory laws are mitigated by three characteristics: exemptions, ability to enforce, and ability to convict. ${ }^{29}$ Only in Australia, New Zealand, and Ontario do helmet wearing laws apply to all age groups. In other jurisdictions, these laws apply only to children. Perhaps because of this, legislators have been reluctant to apply serious penalties for infringement or provide support for their implementation or enforcement. Most infractions are punished by either a warning for first time offenders, or by a fine of $\$ 25-100$, often waived after proof of purchase of a bicycle helmet. All laws specify that the bicycle helmet must conform to one or more nationally or internationally recognized safety standards. Some laws also regulate bicycle passengers, requiring that they wear helmets, sit in child passenger seats, and be at a minimum stage of development.

\section{Parallels with child restraint device and} motorcycle helmet use

The implementation of education and legislative approaches to promote bicycle helmets have many parallels with efforts to promote the use of child restraint devices (CRDs). During the 1960s and 1970s, these devices were identified as being extremely effective in preventing injury and deaths to children and toddler passengers in motor vehicle crashes. A number of different educational campaigns and CRD loaner programs were established to promote the use of car seats. These programs had limited effectiveness. Parents stated that their reasons for not using the car seats included inconvenience, perceived cost, and belief that their children would resist riding in the seats. Knowledge was not a major factor in determining car seat use (although there were some myths such as holding a child in a passenger's arms was safer). Usage of CRDs was positively associated with parent's income, education, and occupation, an association seen in other positive health behaviors. ${ }^{13}$

Led by efforts of the Tennessee Chapter of the AAP, in 1978 Tennessee passed the first state legislation requiring children to be restrained in a car seat. The local chapter of the

Bicycle helmet legislation (October 1994)

\begin{tabular}{ll}
\hline Legislation adopted & Legislation pending \\
\hline Australia (all states and territories) & Alabama \\
New Zealand & Arizona \\
Ontario, Canada (effective 1995) & Delaware \\
California & District of Columbia \\
Connecticut & Florida \\
Georgia & Hawaii \\
Massachusetts & Maryland \\
New Jersey & Michigan \\
New York & Missouri \\
Oregon & Vermont \\
Pennsylvania & Washington \\
Puerto Rico & West Virginia \\
Tennessee & \\
Seventeen local US jurisdictions & \\
\hline
\end{tabular}

AAP decided to promote a legislative, rather than educational approach to car seats, primarily because of the relative lack of success of educational efforts to promote seat belt use for adults, the proved effectiveness of CRDs, and the great cost of hospitalization and rehabilitation for children injured in car crashes. ${ }^{30}$ CRD usage increased from $8 \%$ to $30 \%$ in 1983 . Child deaths in motor vehicle crashes declined by $50 \%$ during this same period. The decrease in child fatalities was inversely related to the number of citations issued by the police for non-use of CRDs. ${ }^{31}$

Similarly, observations throughout the US have shown that without a mandatory wearing law, $40 \%$ to $60 \%$ of motorcyclists wear helmets. When a motorcycle helmet law is implemented, helmet use rises to $100 \%$, when it is repealed, helmet use falls to pre-law levels. The recent passage of the motorcycle helmet use law in California, led to a usage rate of $99 \%$. With adequate enforcement, it is believed that a usage rate of $100 \%$ can be achieved. ${ }^{32}$

Assumptions underlying public health and safety laws

Despite the difficulties of achieving compliance, the history of public health does offer many examples of the effectiveness of legal requirements in modifying risky behaviors. For example, polio and other childhood diseases have come to be recognized as dangers requiring active social intervention, including laws that compel immunization. The desire to reduce dental caries has led state and local governments to mandate by law that municipal water supplies be fluoridated.

US courts have been consistent in affording state and local governments broad authority to enact these types of public health and safety laws, even when the laws significantly limit individual behavior. ${ }^{334}$ From early fire safety laws and worker protection laws to more recent laws such as those requiring window guards in high rise residences and seat belt use by motorists, US courts have adhered to a set of legal doctrines that give primary weight to the obligation and authority of government to protect its citizens from harm. In each instance the legislative assumption has been that voluntary programs will not provide adequate protection to the public. Only by using the authority of government will significant improvements in public health and safety occur.

Bicycle helmet use laws provide an instructive example of how and why laws can influence behavior. It is generally understood that laws serve their social control function through a variety of mechanisms. These include deterrence, citizenship, communication, and moral influence.

Evaluation studies of the effectiveness of the legal deterrence mechanism have been limited in number and the results are often inconclusive. For instance, there is no conclusive information on the deterrent effects of the death penalty. Regardless of rather weak research conclusions, we assume that the effectiveness of laws which require or prohibit certain behaviors is due in part to the fear of 
enforcement. Because of this fear of enforcement, people tailor their behavior in certain desired ways in order to avoid legal consequences. There are, however, other reasons that people may be expected to obey the law. One is a simple citizenship obligation which makes most people view the fact that 'it's the law' as a reason to comply with the law's requirements, even if it is unlikely that a violation will be discovered and penalized. More generally, 'it's the law' serves to influence behavior by communicating social expectations in a clear manner. Laws also provide a model of moral authority that can affect general attitudes and influence behaviors even beyond the specific requirements of particular laws. ${ }^{33} 35$

Compliance with bicycle helmet use laws is due to a complex set of factors that influences behavior. As we have stated, it is unlikely that fear regarding enforcement consequences of helmet laws will result in compliance. The helmet laws have extremely modest penalties and as of this writing have not been rigorously enforced. Bicycle helmet use laws do convey a clear message: society views the wearing of helmets as important, important enough to enact laws which codify the expectation that they will be worn.

There is an important parallel between helmet laws and the national experience with mandatory child restraint laws. Those laws also presented problems in enforcement and contained minimal penalty provisions. Yet they have helped change societal norms regarding the importance of child restraint use. A similar change in societal norms could result from widespread enactment of bicycle helmet use laws.

Another hoped for effect of such laws is that they will counterbalance negative peer pressures. As Robertson has noted: 'Although as yet unsubstantiated by research, it is conceivable that the presence of a law proscribing or requiring certain behaviors is helpful to persons who would otherwise bend to peer pressure'. ${ }^{36}$

Robertson has also suggested several factors that help to enhance compliance with injury prevention laws. Factors, such as severe penalties, are not appropriate with bicycle helmet laws, particularly when children are involved. Other factors, such as permitting few exemptions from compliance with the law have not been abided by when US helmet use laws have been written but are potentially relevant. Several factors, including ease of observing regulated behavior and ease, comfort, convenience of the people to comply are of uncertain importance in enhancing compliance with bicycle helmet laws. Observation of helmet use is not easy if it requires assessing a bicyclist's age. Concerns regarding the perceived discomfort, inconvenience, and pleasure limiting aspects of helmets are often major arguments used to oppose the passage of helmet laws. Perhaps the most relevant and supportive of Robertson's compliance enhancing factors is that 'enforcement can be augmented by persons other than police', in most cases that being parents. Herein lies a viable strategy for in- creasing compliance with children's helmet laws - use the parents as an ally in enforcement.

Waller has suggested several criteria that can help make injury prevention laws more or less likely to be effective in changing behavior. ${ }^{37}$ These criteria can apply to helmet laws. Waller emphasizes the importance of linking law enforcement with public education efforts as 'each reinforces the other'. Educational campaigns to promote bicycle helmet use have been an important adjunct to helmet use laws wherever they have been enacted. Additionally, the desired targeted behavior must be a primary and modifiable cause of injury, subject to deliberation; and be specific, easily understandable, and achievable. Also police must be supportive and knowledgeable regarding an injury prevention law's purpose. Bicycle helmet use laws meet these criteria, but the laws can only be one part of a multifaceted effort to encourage helmet use. An approach that relies on fear of enforcement penalties alone will not succeed.

\section{Objections to helmet laws}

Although helmet laws can play an important part in reducing death, disability, suffering, and costs, bicycle helmet laws are not without their critics. There are three objections commonly directed against helmet laws.

First, even though legally sound and effective, enactment of injury prevention laws may offend important philosophical, political, or economic values. For example, it may be argued that an injury prevention law improperly intrudes into areas of individual autonomy or that the monetary costs associated with a proposed law outweigh any reasonably expected benefits. Second, it may be argued that a law will not work, that it will not achieve its intended purpose and be more effective than a less intrusive alternative. Third, it may be argued that a particular injury prevention law is legally invalid; it violates a specific constitutionally protected right or suffers from some other legal deficiency.

In spite of the persuasiveness of each of these arguments, available legal, ethical, and research experience provide considerable support to justify the implementation of helmet laws. ${ }^{33}$

\section{Future challenges}

The case-control studies conducted in Brisbane and in Seattle have demonstrated that helmets are effective in preventing head injury. Published reports during the last decade indicate that although effective in increasing awareness about the need for helmets, single method educational strategies seem to do little to increase helmet wearing to levels where the head injuries that occur as a result of bicycle crashes can be significantly reduced. After a five year campaign in Seattle, this multifaceted, community wide effort was able to increase helmet use among school aged children to only about $40 \%{ }^{12}$ The health impact of educational strategies will be limited at best, until peer groups - especially 12-16 year olds - can 
positively accept the wearing of helmets. This may occur in time. Based on the limited data we have from Australia and Maryland, legal strategies to require helmet wearing when coupled with intensive community wide educational efforts seem to be extremely effective methods to increase helmet use and subsequently reduce head injury.

The choice of an enforcement strategy to promote helmets presents several difficulties. First, comprehensive helmet laws are difficult to enact; most apply to only the youngest (and non-voting) part of the bicycle riding population. Second, enforcement of bicycle laws is often hampered by numerous exclusions, limited enforcement possibilities, and weak penalties for non-compliance. Initial experiences in Australia and Maryland indicate that community wide multistrategy education programs can change community and individual behavior and can be used to help reduce the financial barriers to helmet purchase. These community efforts are needed to expand the effect of helmet laws.

A legislative strategy for helmet promotion presents a number of challenges. There are a number of research questions that need to be answered:

- Are helmet laws more effective in encouraging wearing among certain age groups? Do laws that address children's helmet use also change helmet wearing behavior in adults? What is the role of parents and companions in increasing helmet use?

- What contribution does community education make to wearing rate in communities with and without helmet legislation?

- What part does enforcement of helmet laws play in increasing use? Is a monetary penalty necessary to increase use? How effective are warnings? What is the effect of waiving the penalty if a helmet is purchased before a court appearance?

- Are increased wearing rates sustained over time? Do education programs continue to be necessary even after the community wearing level has been increased?

- What impact do helmet use laws have on bicycling? Is there an average increase or decrease of bicycling in certain age groups? If ridership is negatively affected, what is the reason?

- Does helmet use effect behavior of motor vehicle operators?

- Methodological issues such as the standard ways to observe helmet use, uniform clinical and epidemiological definitions of head injuries, and precise specification of age, income, and gender target groups are needed to permit comparison of various strategies and thereby evaluate their impact.

Cost effectiveness analyses must be conducted to determine the most efficient ways to promote use. Results from a recent study indicate that a legislative program may be the most inexpensive strategy to promote helmets compared with educational strategies in com- munities and in schools. ${ }^{38}$ These data, however, are preliminary, based on estimated costs for program implementation and incomplete estimates of the costs for the treatment of head injuries.

Critics have questioned the philosophical and political values of helmet use laws. Generally these criticisms have focused on three areas: legal, including those relating to individual freedoms; epidemiological; and practical. Callahan has questioned how far we should depend on laws to help achieve health goals. ${ }^{39} \mathrm{He}$ is concerned that legislating health behavior may result in a kind of health authoritarianism, 'smothering the good of liberty with the good of health'. His feeling is that only if there are no other means to achieve health and safety, should laws be passed, and these laws must be enforceable. In spite of his criticisms, laws to protect society, such as those relating to child labor, seat belts and motorcycle helmets, have always been found valid from a legal standpoint. Nor are they widely seen as intrusive on individuals rights and liberties. We believe that bicycle helmet laws will be seen similarly.

Others oppose bicycle helmets for epidemiological reasons, arguing that the real cause of bicycle injuries is the automobile. ${ }^{40}$ McCarthy argues that efforts would be more fair if directed at motorists, who ultimately are responsible for these fatalities. ${ }^{41}$ The practicality of these suggestions has not been addressed.

We have reservations about the long term impact that helmet laws that apply only to children will have on helmet wearing behavior. There is no epidemiologic justification for these laws to apply only to children, as head injuries occur at similar rates among adult and child riders. Instead, helmet laws for children have been promoted as an expedient way to promote use and get the 'camel's nose under the tent'. Will children, forced to wear helmets because of laws, view the not wearing of helmets as an adult privilege? From a practical standpoint, parents and children often see the purchase and wearing of helmets as inconvenient and expensive - objections similar to those raised by parents whose children were not in car seats during the 1970s and 1980s.

Lastly, as the number of bicyclists who are wearing helmets increases, there will undoubtedly be an increase in the number of head injuries that occur in bicyclists wearing helmets. Will there be political backlash to this? Will helmets be judged by the public as ineffective? Will bicycle helmet laws be repealed as motorcycle laws were in the US during the 1970s? Are we prepared to defend the usefulness of helmets in preventing and in reducing head injury?

There is good evidence that helmet laws increase helmet use in children. Laws are an efficient and seemingly socially acceptable means of rapidly increasing helmet use in young children, especially when combined with community education efforts that promote helmet wearing. Preliminary evidence indicates that helmet laws are as effective as seat belt and child restraint laws were in increasing 
their use. Perhaps helmet laws will be the breakthrough in road user protection in the 1990 s, just as seat belts and car seats were in the last two decades. The potential strategy is available substantially to decrease the morbidity and mortality due to bicycle injuries. We need to refine our knowledge of it.

1 Ayres E. Breaking away. World Watch 1993; 6: 10-19.

2 Rodgers GB. Bicycle use and hazard patterns in the United States, and options for injury reduction. Washington, DC: United States Consumer Product Safety Commission, 1993.

3 Bicycle Institute of America. Bicycling reference book, 1992-1993 edition. Washington DC: Bicycle Institute of America, 1993.

4 Centers for Disease Control. Bicycle-related injuries: data from the national electronic injury surveillance system. $M M W R$ 1987; 36: 269-71.

5 Tinsworth DK, Polen C, Cassidy S. Bicycle-related injuries: injury, hazard and risk patterns. In: Rodgers GB, ed. Bicycle use and hazard patterns in the United States, and options for injury reduction. Washington, DC: United States Consumer Product Safety Commission, 1993.

6 Kraus JF, Fife D, Conroy.C. Incidence, severity, and outcomes of brain injuries.

7 Fife D, Davis J, Tate L, et al. Fatal injuries to bicyclists: the experience in Dade County, Florida. F Trauma 1983; 23: 745-55.

8 Sacks JJ, Homgreen P, Smith SM, et al. Bicycle associated head injuries from deaths in the United States from 1984 through 1988. $₹ A M A 1991 ; 266: 3016-18$.

9 Thompson RS, Rivara FP, Thompson DC. A case-control study of the effectiveness of bicycle safety helmets. N Engl F Med 1989; 320: 1361-7.

10 Thomas S, Acton C, Nixon J, et al. Effectiveness of bicycle helmets in preventing head injury in children: casecontrol study. $B M \Im$ 1994; 308: $173-6$.

11 Bergman AB, Rivara FP, Richards DD, et al. The Seattle children's bicycle helmet campaign. Am $\mathcal{F}$ Dis Child 1990 144: $727-31$.

12 Rivara FP, Thompson DC, Thompson RS, et al. The Seattle children's bicycle helmet campaign; changes in helmet use and head injury admissions. Pediatrics 1994; 93: 567-9.

13 Erikson MP, Gielen AC. The application of health education principles to automobile child restraint programs. Health Educ $Q$ 1983; 10: 35-7.

14 Pedergast RA, Ashworth CD, DuRant RH, Litaker M Correlates of children's bicycle helmet use and short-term Correlates of children's bicycle helmet use and short-term 354-8.

15 Morris BAP, Trimble NE. Promotion of bicycle helmet use among schoolchildren: a randomized clinical trial. Can $\mathcal{f}$ Public Health 1991; 82: 92-4.

16 Cushman R, Down J, MacMillan N, et al. Helmet promotion in the emergency room following a bicycle injury: a randomized trial. Pediatrics 1991; 88: 43-7.

17 Cushman R, James W, Waclawik H. Physicians promoting bicycle helmets for children: a randomized trial. $A m$ Public Health 1991; 81: 1044-5.
18 Miller JR, Pless IB. Child automobile restraints: evaluation of health education. Pediatrics 1977; 59: 907-11.

19 Boyle Jr WE. Bicycle helmet promotion: what works? American Academy of Pediatrics national bicycle safety campaign. Proceedings of the Second World Conference on Injury Control. Atlanta, GA: 20-23 May 1993.

20 Parkin P, Spence L, Hu X, et al. Evaluation of a subsidy program to increase helmet use in low-income families. Proceedings of the Second World Conference on Injury Control. Atlanta GA: 20-23 May 1993.

21 DiGuiseppi CG, Rivara FP, Koepsel T, et al. Bicycle helmet use by children: evaluation of a community-wide helmet campaign. $\mathcal{F} A M A$ 1989; 262: 2556-61.

22 Dannenberg AL, Cote TR, Kresnow MJ, et al. Bicycle helmet use by adults: the impact of companionship. Public Health Rep 1993; 108: 212-7.

23 McDermott FT, Klug GI. Differences in head injuries of pedal cyclist and motorcyclist casualties in Victoria. Med $\exists$ Aust 1983; ii: $30-2$.

24 Wood T, Milne P. Head injuries to pedal cyclists and the promotion of helmet use in Victoria, Australia. Accid promotion of helmet use in

25 Cameron MH, Vulcan AP, Finch CF, et al. Mandatory bicycle helmet use following a decade of helmet promotion in Victoria, Australia - an evaluation. Accid Anal Prev 1994; 26: 325-37.

26 Scheidt PC, Wilson MH, Stern MS. Bicycle helmet law for children: a case study of activism in injury control. Pediatrics 1992; 89: 1248-50.

27 Cote TR, Sacks JJ, Lambert-Huber DA, et al. Bicycle helmet use among Maryland children: effect of legislation and education. Pediatrics 1992; 89: 1216-20.

28 Dannenberg AL, Gielen AC, Beilenson PL, et al. Bicycle helmet law and educational campaigns: an evaluation of trategies to increase children's helmet use. $A m \mathcal{F}$ Public Health 1993; 83: 667-74.

29 Martinez R. Injury control: a primer for physicians. Ann Emerg Med 1990; 19: 72-7.

30 Sanders RS, Dan BB. Bless the seats and the children: the physician and the legislative process [Editorial]. $\mathcal{f} A M A$ 1984; 252: 2613-4

31 Decker MD, Dewey MJ, Hutcherson RH, et al. The use and efficacy of child restraint devices. The Tennessee experience, 1982 and 1983. FAMA 1984; 252: 2571-5.

32 Kraus JF, Peek C, Williams A. Compliance with the 199 California motorcycle helmet use law. Am $\mathcal{f}$ Public Health 1995; 85: 96-9.

33 Christoffel T, Teret SP. Protecting the public: legal issues in injury prevention. New York: Oxford University Press, 1993.

34 Christoffel T. Health and the law: a handbook for health professionals. New York: Free Press, 1982.

35 Rabin RL, Sugarman SD. Smoking policy: law, politics, and culture. New York: Oxford University Press, 1993.

36 Robertson LS. Injuries: causes, control strategies, and public policy. Lexington, MA: Lexington Books, 1983.

37 Waller JA. Injury control: a guide to the causes and prevention of trauma. Lexington, MA: Lexington Books, 1985.

38 Brown R, Hatziandreu E, Sacks J, et al. Cost effectiveness of three programs to increase the use of bicycle helmets in three programs to increase the use of bicycle helmets in the United States. Proceedings of the Second World Confere

39 Callahan D. Legislating safety - how far should we go ? [Editorial]. N Engl fै Med 1989; 320: 1412 .

40 DeMarco $T$. The use of bicycle helmets should not be mandatory. Can Med Assoc f 1993; 149: 342-4.

41 McCarthy $M$. Do cycle helmets prevent serious head injury? Cycling without helmets. BMF 1992; 305: 881-2.

'They [the Safe Kids Campaign] have changed the way we think about childhood injury. And you know how hard it is to change the way grown-ups think. They saw kids being killed in car crashes, and they said they did not have to die that way ... They saw that these deaths could be prevented, and they got that message out to America. What an idea, and what a powerful message' (Mark Rosenberg, Director of the National Center for Injury Prevention and Control (CDC, Atlanta) in the 1994 Annual Report of the National Safe Kids Campaign).

Observed without comment: funding levels (in millions USS) for US public health programs during 1994 ranged from 543.2 for AIDS; 123 for chronic and environmental disease prevention; 99.8 for sexually transmitted diseases; etc. At the bottom of the list was injury control, 39.3. 